\title{
Computer Game Approach Focusing on Social Communication Skills for Children with Autism Spectrum Disorder: An Initial Study
}

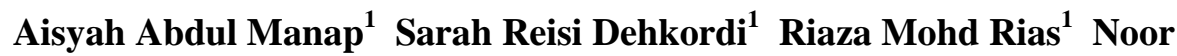 \\ Aziezah Sardan \\ ${ }^{1}$ Faculty of Computer and Mathematical Sciences \\ University Technology MARA, 40450 Shah Alam Selangor, Malaysia
}

\begin{abstract}
Autism Spectrum Disorders (ASD) and autism are both general terms for a group of complex disorders of brain development. ASD is characterized by difficulties with communication, social deficits, stereotyped or repetitive behaviours and interests. One of the major reasons behind the push to use technology and multimedia to assist interaction with children diagnosed with ASD is that they have shown a preference for, as well as a fascination with, "visual stimuli" such as computer applications, games, and videos. Primordial purpose of this study is to synthesize a survey regarding social problems and situations faced by children with autism. A number of questionnaires for parents and teachers with a semi-structured interview for five doctors and eleven therapists were conducted to identify basic problems of children with Autism and psychological methods for each problem.
\end{abstract}

Keywords: Autism Spectrum Disorders, games, social skills

\section{Introduction}

Autism Spectrum Disorder (ASD) is a set of neurodevelopmental disorder characterized by impairment in social interaction, communication skills and in behaviour, which is restricted and repetitive [1]. These signs of autism are observed in the early years of a child's life. The main cause of people with autism is unclear. In the worldwide, the prevalence of autism is about 1-2 per 1,000 people [1]. According to the National Autism Society of Malaysia (NASOM), there has been a 30\% increase in the organization's intake of individual with autism for the past three years in Malaysia. It also has been reported that the number of people with Autism is increasing at a high rate in recent decades. Thus, it is necessary to find a new and effective way for them to develop their skills and to help them to be able to contribute in the society even with their limitations.

Three predominant problems encountered by children with Autism are socialization problems, communication problems and behavioural problems. There are no two Autistic children are 
alike but there are several common problems among them that have been reported such as sensory abnormalities, savant skills, problem with understanding others' feelings and emotions, hyperactivity, attention, motivation and memory problems. There are limited tools and methods in order to support children with Autism especially in psychotherapy sessions. Conventional methods are not effective in many cases [2] because it is difficult for therapists to ensure the autistic children to attend in therapy sessions. Sometimes, children refused to finish the sessions because they feel anxious and uncomfortable. One of the main problems about children with Autism is that they confronted with difficulties in communication with others. As a result, it is difficult for them to share their feelings and problems with their therapists.

This paper looks at some related works on the usage of games and its benefits for these special children. To gain more insight on the current situation and problems faced by ASD children, a series of semi-structured interviews and surveys were carried out on parents with ASD children, teachers, doctors, and therapist who associate with ASD patients.

\section{Games Technology for Autism Spectrum Disorder}

There is a significant need to develop technology that can help Autistic children in education since characteristics of children with autism limit their opportunity to take advantage of formal education [3]. Hence, it is extremely crucial to establish effective educational methods which include educational technology for children with autism [3]. Several examples of using technology as a third party in therapy sessions are some animations, CD/DVDs and games. The electronic teaching software available in CD/DVDs cannot be customized for a special child [4]. Software and CD/DVDs that are available cannot support all the Autistic children nor solve their problems because the users are not in the same level of understanding. Using game in therapy already proven as an efficient tool to support children in therapy session [5].

Children will learn new things by playing and having fun. Playing provides the opportunity to make mistakes without getting harmed [3] and children will learn through their experiences in which obtained from their mistakes in a game. Since children play computers and internet games much more day by day [6], it would be easier to engage a child to play games on computer or other devices rather than attending therapy session. In order to use games for therapy sessions, it should be concerned that the particular games support the limitation of autistic children. This is because using games for therapy or education is completely different from normal games that have been designed merely for entertainment. Educational or therapy purpose should be the supreme goal of using game for Autistic children. In that case, some components such as environment of the game, sounds, colours and game`s characters should be designed based on the child's limitations.

Thus, in a therapy session, while children are playing a game on computer or other devices, they will learn new things and will forget that they are in a therapy session because they pay full attention to the game. This method can help them engage with the computer games and can improve their skills indirectly in a safe and comfortable places, for instance, their houses or schools meanwhile their parents or teachers can observe and record their improvement. 
Findings suggest that computer-based technologies might be useful educational aides for students with ASD [7]. Computer games provide a safe, secure, and less anxious environment for autistic users [8]. The users can play and practice and learn by their mistakes at their own place. According to Hassan [9], children with Autism are less resistant to the use of technology in learning. Due to the fact that users may have different abilities, capacities and needs, tools must be flexible in order to adapt to different users [10] because using regular game as a third party in therapy session can lead to failure in achievements.

Along these lines, computers, laptops, and other devices have been employed to teach a range of skills to children with ASD. Most of the games have been designed for computers and there are minimal numbers of games that can be played on touch screen devices. Touch screen devices such as tablets provide freedom between different locations. Tabletop offered intuitive and natural interactions and allows for rough motor skills and idefinite manipulation. It is more advantage rather than using mouse pointer [11].

\section{Related Work}

During the last few years, researchers have been working on educational programs such as board game, online game therapy, video game and computer games. Researchers used many devices such as mobiles and touch screen devices for users with special needs like Autism. There are two main purposes of using game for children with Autism. The first one is therapy purpose and the second one is educational purpose. Autism games technologies classifications are shown in Table 1.
Table. 1: Autism Games Technologies Classification

\begin{tabular}{|l|l|l|}
\hline \multirow{7}{*}{ Mobile } & $\begin{array}{l}\text { Author/ } \\
\text { Year }\end{array}$ & Purpose \\
& $\begin{array}{l}\text { Femandez, } \\
\text { 2013 [10] }\end{array}$ & $\begin{array}{l}\text { Develop basic } \\
\text { skills }\end{array}$ \\
\cline { 2 - 3 } & $\begin{array}{l}\text { Uturi et al., } \\
\text { 2011 [13] }\end{array}$ & $\begin{array}{l}\text { First Aid } \\
\text { learning }\end{array}$ \\
\hline Computer & $\begin{array}{l}\text { Jain et al., } \\
\text { 2012 [2] }\end{array}$ & $\begin{array}{l}\text { Facial } \\
\text { expression }\end{array}$ \\
\cline { 2 - 3 } & $\begin{array}{l}\text { Irish, 2013 } \\
\text { [8] }\end{array}$ & $\begin{array}{l}\text { Social } \\
\text { communication }\end{array}$ \\
\cline { 2 - 3 } & $\begin{array}{l}\text { Finkelstein, } \\
\text { 2009 [14] }\end{array}$ & $\begin{array}{l}\text { Teach Emotion } \\
\text { Recognition } \\
\text { Programming } \\
\text { Logic }\end{array}$ \\
\hline
\end{tabular}

\section{Discussion}

To understand the problems and situations faced by children with Autism, some essential needed studies were done as follows.

\subsection{Consultation with doctors and experts}

A semi-structured interview was conducted with five doctors and eleven therapists to identify the basic problems of children with Autism and psychological methods for each problem. This will be helpful in a way to recognize Autistic children`s main disabilities as well as to assist in finding specific goals for this research. Fig 1 shows the result of the consultation in order to find out which problem is the most crucial about children with Autism. The value number 1 in the Fig 1 indicates the lowest priority of the problem and number 3 indicates the highest priority. 


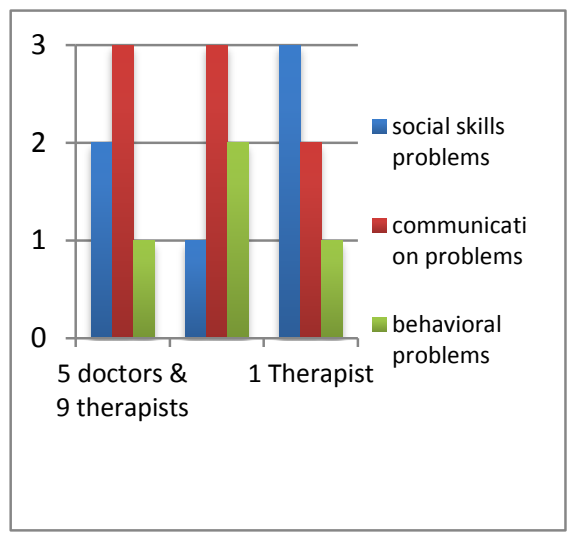

Fig. 1: Consultation's Result

Fig 1 shows that 5 doctors and 9 therapists selected communication problems as the most crucial problem among children with autism followed by social skills problems and behavioral problems respectively.

Based on the result from Fig 1, ten basic problems related to social skills and communication skills were selected. Fig 2 shows the result presenting five problems that have the highest rate as below.

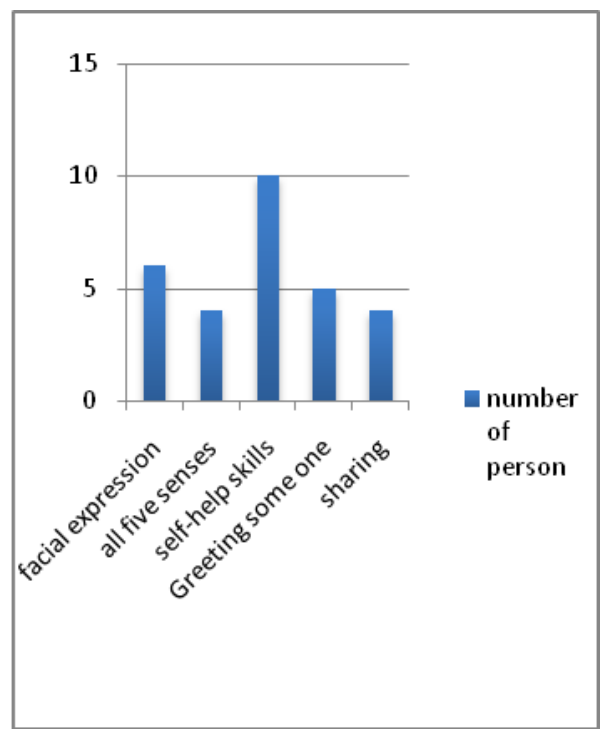

Fig. 2: Problems Related with Autism

\subsection{Interview with teachers and parents}

A separate questionnaire for parents and teachers of the participants help us to set the main aim of this research among problems with the highest priority and to recognize the components that should be concerned in a game based on the psychological methods. Fig 3 shows the average answer of teachers and parents to each problem. The average is out of 4 and shows all of the participants have serious problem in communication skills.

About one third of individuals with autism do not have enough natural skills in their speeches that can meet the necessity of their daily communications. The problem in communication is based largely upon speech and language problem [12].

As the figure shows parents' reports are biased, the result presents that parents cannot judge their child fairly and in first two column parent's average is more than teachers but for self-help skills, parent's rate is less than teacher because some self-help skills such as "wear on a cloth" or "brushing the teeth" are some skills that only parents can observe their child and teachers do not know clearly how the child doing self-skills.

As a result based on the Figure 3 initiating interaction and responding to initiations were selected as a main problem of the 14 participants with Autism Spectrum Disorder. 


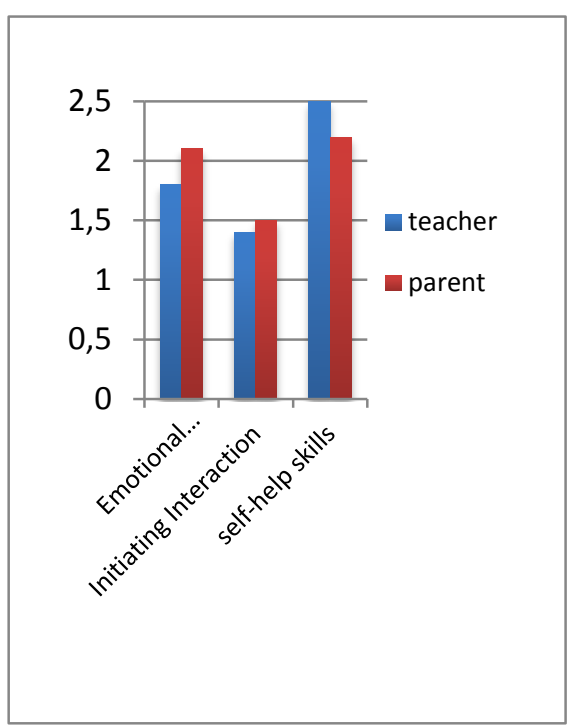

Fig. 3: Questionnaires with teachers and parents

\section{Conclusion}

Primordial purpose of this study is to design a game for children with Autism to improve their social communication skills. The result of this research shows that lack of social skills is the most prominent problem regarding children with autism. Most common children learn social and communication skills by watching their peers, experimenting in imitation and refining their skills. On the other hand, children with autism need specific teaching methods in these skills since they find it difficult to do so. Social skills need to be broken down, explained, and practiced so that children with an ASD can absorb them at a level that makes sense to them. Computer games can be one of the medium for children with autism to help improve the social skills during the therapy sessions. The limitation of this study is that the domain area of this research is only within
Malaysian environment only. Other countries might gain different result and different problems as children with autism are not alike and have differences in their limitation.

\section{Acknowledgment}

The authors would like to thank the Research Cluster Fund (RCF) and Research Management Institutes (RMI) at University Technology MARA for their supports.

\section{References}

[1] Report, M. W., "Prevalence of autism spectrum disorders--Autism and Developmental Disabilities Monitoring Network", 14 sites, United States, 2008. Morbidity and mortality weekly report. Surveillance summaries (Washington, D.C. : 2002), 61(3), 1-19. Retrieved from http://www.ncbi.nlm.nih.gov/pubmed /22456193, 2012

[2] S. Jain, B. Tamersoy, Y. Zhang, and J. K. Aggarwal, "An Interactive game for teaching facial expressions to children with autism spectrum disorders" The University of Texas at Austin V . Orvalho Inst . de Telecomunicac Fac . de $\mathrm{Ci}^{\wedge}$ encias da Universidade do Porto, (May), pp. 2-4, 2012.

[3] S. Cankaya, and A. Kuzu, "Investigating the characteristics of educational computer games developed for children with autism: a project proposal" Procedia - Social and Behavioral Sciences, vol. 9, pp. 825-830, 2010.

[4] M. R. Rahman,, S. Naha, P. C. Roy, I. Ahmed, S. Samrose, M. M. Rahman, and S. I. Ahmed, "A-class: A classroom software with the support for diversity in aptitudes of 
autistic children," 2011 IEEE

Symposium on Computers \&

Informatics, pp. 727-731, 2011.

[5] J.C.A. Silva, S. Fels, and J.M.R. Villena, "Design of a web-based therapist tool to promote emotional closeness," Proceedings of $\mathrm{CHI}$ Extended Abstracts, 3565-3570, 2010.

[6] S. Mumtaz, “Children's enjoyment and perception of computer use in the home and the school," Computers and Education, vol. 36, no. 4, pp. 347362, 2001.

[7] D. M. Kagohara, J. Sigafoos, D. Achmadi, M. O'Reilly, and G. Lancioni, "Teaching children with autism spectrum disorders to check the spelling of words," Research in Autism Spectrum Disorders, vol. 6, no. 1, pp. 304-310, 2012.

[8] J. E. N. Irish, "Can I sit here? A review of the literature supporting the use of single-user virtual environments to help adolescents with autism learn appropriate social communication skills," Computers in Human Behavior, 2013.

[9] A. Z. Hassan, B. T. Zahed, F. T. Zohora, J. M. Moosa, T. Salam, M. M. Rahman, H. S. Ferdous, et al. "Developing the Concept of Money by Interactive Computer Games for Autistic Children." 2011 IEEE
International Symposium on

Multimedia, pp. 559-564, 2011.

[10] Á. Fernández-López, M. J. Rodríguez-Fórtiz, M. L. RodríguezAlmendros, and M. J. MartínezSegura, "Mobile learning technology based on iOS devices to support students with special education needs," Computers \& Education, vol. 61, pp. 77-90, 2013.

[11] W. Chen, "Multitouch Tabletop Technology for People with Autism Spectrum Disorder: A Review of the Literature," Procedia Computer Science, vol. 14, no 1877, pp. 198207, 2012.

[12] M. M. Rahman, S. M. Ferdous, and S. I. Ahmed, "Increasing Intelligibility in the Speech of the Autistic Children by an Interactive Computer Game," 2010 IEEE International Symposium on Multimedia, pp. 383-387, 2010.

[13] Z. S. D. Urturi, A. M. Zorrilla, and Z, B. G., "Serious Game based on Fi irst Aid Education for individuals wi ith Autism Spectrum Disorder ( ASD ) using Android Mobile Devices", pp. 223-227, 2011.

[14] S. L. Finkelstein, A. Nickel, E. A. Suma, and T. Barnes, (n.d.) cMotion: A New Game Design to Teach Emotion Recognition and Programming Logic to Children using Virtual Humans, pp. 249-250. 